\title{
Semibatch Surfactant-Free Emulsion Polymerization of Butyl Acrylate
}

\author{
Chorng-Shyan CHERN and Chi-Huei LiN \\ Department of Chemical Engineering, \\ National Taiwan Institute of Technology, \\ Taipei, Taiwan 10672, Republic of China
}

(Received June 5, 1995)

\begin{abstract}
The latex particles can maintain an appreciable stability by the limited flocculation process during the semibatch surfactant-free emulsion polymerization of butyl acrylate, especially at higher total solids content. Intensive agitation (e.g., $800 \mathrm{rpm}$ in a 1-liter reactor) can result in a significant amount of coagulum in addition to limited flocculation. At a common reaction time, the latex particle size increases with an increase in the monomer feed rate. A large amount of scrap is formed for the run with the highest monomer feed rate. At any time during polymerization, the particle size first increases to a maximum and then decreases with an increase in the initiator concentration. The run with the lowest level of initiator shows the worst latex stability because there is an insufficient supply of sulfate end-groups to stabilize the growing particles. However, a significant amount of coagulum is observed for the run with a higher level of initiator due to the ionic strength effect. The optimum latex stability occurs at a point close to an initiator level of $0.19 \%$. The effect of buffer on the latex particle size and stability is significant, again, due to the ionic strength effect. The critical flocculation concentration is $0.45 \mathrm{~N} \mathrm{NaCl}$.

KEY WORDS Emulsion Polymerization / Surfactant-Free / Semibatch /

Latex Particles / Butyl Acrylate / Latex Stability /
\end{abstract}

Semibatch emulsion polymerization ${ }^{1-13}$ is an important process for the production of polymers for the industries of coatings, adhesives, thermoplastics, and rubbers. A latex product consists of innumerable submicron polymer particles dispersed in water. These particles are generally stabilized by anionic surfactants (e.g., sodium lauryl sulfate) and/ or nonionic surfactants (e.g., nonylphenol$40 \mathrm{~mol}$ ethylene oxide adduct). Nevertheless, the surfactants remained in the latex product can have a negative effect on the application properties such as adhesion of the pressuresensitive adhesives and film formation and water resistance of the coating materials because the small and mobile surfactant molecules tend to migrate to the surface layer of the polymeric film.

One approach to overcome this problem is to adopt the surfactant-free emulsion polymerization technique. ${ }^{14-19}$ In this case, only the sulfate end-group ( $\left.\mathrm{SO}_{4}^{-}\right)$attached onto the particle surface, derived from initiator (e.g., sodium persulfate), is responsible for stabilizing the latex particles. Thus the latex stability can be greatly reduced and a significant amount of coagulum can form during the monomer addition period. Removal of coagulum by filtration is necessary since the filterable solids can have a negative effect on the application properties (e.g., the gloss of the polymeric coatings). The reactor needs to be shut down for cleaning when the reactor scrap accumulates to an unacceptable level. In addition, the latex particles can grow in size by mild aggregation of a few particles in order to maintain an appreciable colloidal stability. For example, the tremendous particle surface area generated during the particle nucleation period can result in a lower particle surface charge density and, hence, a lower potential energy barrier against flocculation. Therefore, the re- 
pulsive force among the interactive particles is not high enough to keep these particles from flocculation. Such a flocculation process will lead to a decrease in the particle surface area and, consequently, increase the particle surface charge density. The flocculation process will diminish when the particle surface charge density increases to a certain level and most of the flocculated particles still can be stably dispersed in water. Such a limited flocculation process $^{20,21}$ can make the task of particle size control more difficult. All these factors will cause significant problems to the plant production of emulsion polymers.

References 14-19 all dealt with batch surfactant-free emulsion polymerization. To the best of our knowledge, the literature of semibatch surfactant-free emulsion polymerization has been nil. Thus, the objective of this work was to investigate the effects of important reaction variables (e.g., the agitation speed, monomer feed rate, concentrations of initiator and buffer in the initial reactor charge, and total solids content of the latex product) on semibatch surfactant-free emulsion polymerization of butyl acrylate. In particular, we will focus our attention on the critical issues concerning the particle size control and colloidal stability. As mentioned above, waterborne pressure-sensitive adhesives made by the emulsifier-free technique generally show better adhesive properties. The results obtained from this work should be useful to tape and label industries.

\section{EXPERIMENTAL}

\section{Materials}

The chemicals used were butyl acrylate (BA) (Formosa Plastics Co.), sodium persulfate (Riedel-de Haen), sodium bicarbonate (Riedel-de Haen), sodium hydroxide (Riedelde Haen), hydrochloric acid (Nacalai Tesque, Inc.), sodium chloride (Riedel-de Haen), nitrogen, and deionized water (Barnsted, Nanopure Ultrapure Water System, specific conductance $\left.<0.057 \mu \mathrm{S} \mathrm{cm}^{-1}\right)$. The monomer BA was distilled under reduced pressure before use. All other chemicals were used as received.

\section{Polymerization Process}

Semibatch emulsion polymerization was carried out in a 1-liter glass reactor equipped with a 4-bladed agitator, a thermometer, and a condenser. A typical recipe is shown in Table I. The total solids content was at least $40 \%$ for most of the experiments so that the latex products may be commercially viable. The initial reactor charge (including water and sodium bicarbonate) was purged with nitrogen for $10 \mathrm{~min}$ to remove dissolved oxygen while heated to $80^{\circ} \mathrm{C}$, followed by addition of the initiator solution. The monomer was then fed to the reactor over a prescribed period of time (e.g., $4 \mathrm{~h}$ for the experiment with a target total solids content of $40 \%$ ) by a FMI pump. The reaction temperature was kept at $80^{\circ} \mathrm{C}$ throughout the reaction. After the end of the monomer feed, the reaction system was maintained at $80^{\circ} \mathrm{C}$ for one more hour to reduce the level of residual monomer.

\section{Characterization of Latexes}

The latex product was filtered through a 40mesh $(0.42 \mathrm{~mm})$ screen and a 200 -mesh $(0.074$ $\mathrm{mm}$ ) screen in series to collect the filterable solids. Scrap adhering to the agitator, thermometer, and reactor wall were also collected. Total solids content was determined by the gravimetric method. The yield of the latex product is defined as the percentage of the total monomer converted to polymer. Particle size data were obtained from the dynamic light scattering method (Otsuka, Photal LPA-3000/ 3100). The transmittance of the latex sample (total solids content $=0.0128 \%$ ) was measured by a spectrophotometer (Metertek SP-810) at $540 \mathrm{~nm}$ for determination of the critical flocculation concentration (CFC). The $\mathrm{pH}$ and ionic strength of the latex sample were adjusted by using $\mathrm{NaOH}, \mathrm{HCl}$, and $\mathrm{NaCl}$. The sample was allowed to stand at room temperature for 
$1 \mathrm{~h}$ before the transmittance measurement.

The zeta potential $(\zeta)$ of the latex particles was measured by Malvern's Zetamaster. For appropriate measurements, the latex product was diluted with water that had the same $\mathrm{pH}$ and conductivity as the original latex. The $\mathrm{pH}$ and conductivity of the dilution water were adjusted by using $\mathrm{HCl}, \mathrm{NaOH}$, and $\mathrm{NaCl}$. Thus, after sample preparation the latex particles should be exposed to a similar aqueous environment as compared to the original latex. Five measurements were made for each latex sample and the average of these five measurements was reported as the $\zeta$ of the finished product.

\section{RESULTS AND DISCUSSION}

\section{Effect of Total Solids Content}

The parameter, total solids content, was selected for study in the first series of experiments. The recipe shown in Table $I$ has a total solids content of $40 \%$ at the end of the monomer feed (total weight of monomer $W_{\mathrm{m}}=$ $223.7 \mathrm{~g}$ ). The total solids content at the end of polymerization was varied from $20 \%$ to $60 \%$. For the experiment with a total solids content greater than $40 \%$ (e.g., $55 \%$ ), the recipe shown in Table I was still valid except that more monomer (e.g., $W_{\mathrm{m}}=307.7 \mathrm{~g}$ ) was added to the reactor to achieve the target total solids content. The monomer feed rate was kept

Table I. A typical recipe for semibatch surfactant-free emulsion polymerization of butyl acrylate

\begin{tabular}{lcc}
\hline & Chemicals & Weight/g \\
\hline Monomer feed & $\mathrm{BA}$ & 223.7 \\
Initial reactor charge & $\mathrm{H}_{2} \mathrm{O}$ & 322.0 \\
& $\mathrm{NaHCO}_{3}$ & 0.66 \\
Initiator solution & $\mathrm{H}_{2} \mathrm{O}$ & 15.0 \\
& $\mathrm{Na}_{2} \mathrm{~S}_{2} \mathrm{O}_{8}$ & 0.65 \\
Total weight & & 562.01
\end{tabular}

Theoretical total solids content $=40 \%$

Monomer feed rate $=0.93 \mathrm{~g} \mathrm{~min}^{-1}$ constant $(0.93 \mathrm{~g} / \mathrm{min})$ throughout this series of experiments. The concentration of initiator $\left(\mathrm{Na}_{2} \mathrm{~S}_{2} \mathrm{O}_{8}\right)$ and buffer $\left(\mathrm{NaHCO}_{3}\right)$ was $0.19 \%$ and $0.20 \%$, respectively, based on total water shown in the recipe. The agitation speed was $600 \mathrm{rpm}$.

The average interparticle distance, $H$, is a measure of the degree of interaction among the latex particles. The smaller the parameter $H$ is, the more crowded the colloidal system is and, as a result, the greater the interaction among the particles is. For monodisperse particles, $H$ is a function of total solids content according to the following equation ${ }^{22}$ :

$$
H / r=2\left[\left(74 \rho_{\mathrm{p}} / w_{\mathrm{p}}\right)^{1 / 3}-1\right]
$$

where $r$ is the particle radius, $\rho_{\mathrm{p}}$ is the density of polymer, and $w_{\mathrm{p}}$ is the weight percentage of particles in the latex which is linearly proportional to total solids content.

Figure 1 shows the calculated relationship between the dimensionless parameter $\mathrm{H} / \mathrm{r}$ (relatively mean free path length between two particles) and total solids content. The parameter $H / r$ decreases rapidly with an increase in the total solids content. For example, $H / r$ decreases about one order of magnitude and $r$ increases only from $408 \mathrm{~nm}$ to $614 \mathrm{~nm}$ as the

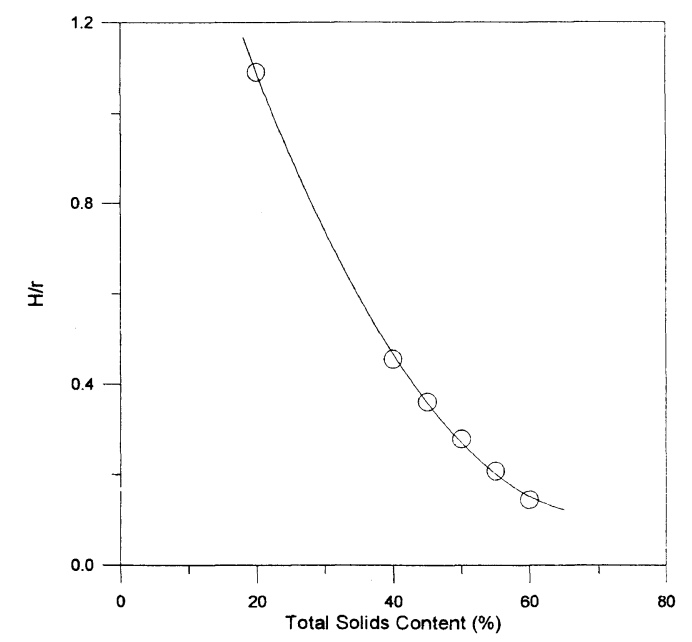

Figure 1. The calculated relatively mean free path length between two particles $(H / r)$ as a function of total solids content for semibatch emulsion polymerization. 
total solids content increases from $20 \%$ to $60 \%$. Thus, the higher the total solids content is, the more crowded the colloidal system is and, hence, the greater the interaction among the particles is.

The properties of the finished products are listed in Table II. To test the batch-to-batch variations, one of the experiments (recipe: the concentrations of initiator and buffer were $0.19 \%$ and $0.20 \%$, respectively, the total solids content was $50 \%$, the monomer feed rate was $0.93 \mathrm{~g} / \mathrm{min}$, and the agitation speed was 600 rpm) was carried out twice. As shown in Table II, the average of the particle size, $d_{\mathrm{w}} / d_{\mathrm{n}}$, total scrap, 200-mesh filterable solids, $\zeta$, and yield are $581 \pm 3 \mathrm{~nm}, 1.13 \pm 0.01,1.5 \pm 0.2 \%, 300 \pm$ $100 \mathrm{ppm},-91 \pm 9 \mathrm{mV}$, and $88 \pm 3 \%$, respectively, in which the parameter $d_{\mathrm{w}} / d_{\mathrm{n}}$ is the polydispersity index of the particle size distribution. The reproducibility of the above experiment is reasonably good except the data of 200-mesh filterable solids. The issue of reproducibility of the experiments will be further addressed later (see discussion on the particle size data in Figure 2). The total amount of scrap data (including 40-mesh filterable solids, 200-mesh filterable solids, and the coagulum adhering to the agitator, thermometer, and reactor wall) show that the run with a total solids content greater than $40 \%$ is unsatisfactory. The 200-mesh filterable solids data are relatively high except the runs with $40 \%$ and $55 \%$ solids. These experimental results seem to imply that the parameter, total solids content, does not play an important role in determining the stability of emulsion polymers. However, as will be shown below, the growing particles can experience significant limited flocculation in the course of polymerization.

The volume of the monomer-swollen polymer particle, $V_{\mathrm{p}}$, can be calculated according to the following equation (i.e., a mass balance around the semibatch reaction system) if both nucleation of a second population of primary particles (secondary nucleation) and coagulation of the latex particles do not take place during the monomer addition period.

$$
\begin{aligned}
V_{\mathrm{p}} & =(\pi / 6) d_{\mathrm{p}}^{3} \\
& =W_{\mathrm{m}}\left(t / t_{\mathrm{t}}\right) /\left\{N_{\mathrm{p}} V_{\mathrm{t}}\left[\rho_{\mathrm{m}}\left(1-\Phi_{\mathrm{p}}\right)+\rho_{\mathrm{p}} \Phi_{\mathrm{p}}\right]\right\}
\end{aligned}
$$

where $d_{\mathrm{p}}$ is the particle diameter, $t$ is the reaction time after the start of the monomer feed, $t_{\mathrm{t}}$ is the total monomer feed time, $N_{\mathrm{p}}$ is the number of particles per unit volume of latex, $V_{\mathrm{t}}$ is the total volume of the finished product, $\rho_{\mathrm{m}}$ is the density of monomer, and $\Phi_{\mathrm{p}}$ is the volume fraction of polymer in the particles. The ratio $t / t_{\mathrm{t}}$ represents the fraction of the monomer that has been added to the reactor. Rearrangement of eq 2 results in the following equation.

$$
\begin{aligned}
\log \left(d_{\mathrm{p}}\right)= & 1 / 3 \log (t) \\
& +1 / 3 \log \left(6 W _ { \mathrm { m } } \left\{\pi t_{\mathrm{t}} N_{\mathrm{p}} V_{\mathrm{t}}\right.\right. \\
& \left.\left.\times\left[\rho_{\mathrm{m}}\left(1-\Phi_{\mathrm{p}}\right)+\rho_{\mathrm{p}} \Phi_{\mathrm{p}}\right]\right\}\right)
\end{aligned}
$$

Thus, a plot of $\log \left(d_{\mathrm{p}}\right)-v s .-\log (t)$ should give a straight line with a slope of $1 / 3$ if both secondary nucleation and coagulation do not take place during polymerization.

Figure 2 shows the $\log \left(d_{\mathrm{p}}\right)-v s$. $\log (t)$ data for the experiments with total solids content ranging from $20 \%$ to $60 \%$. Since the total amount

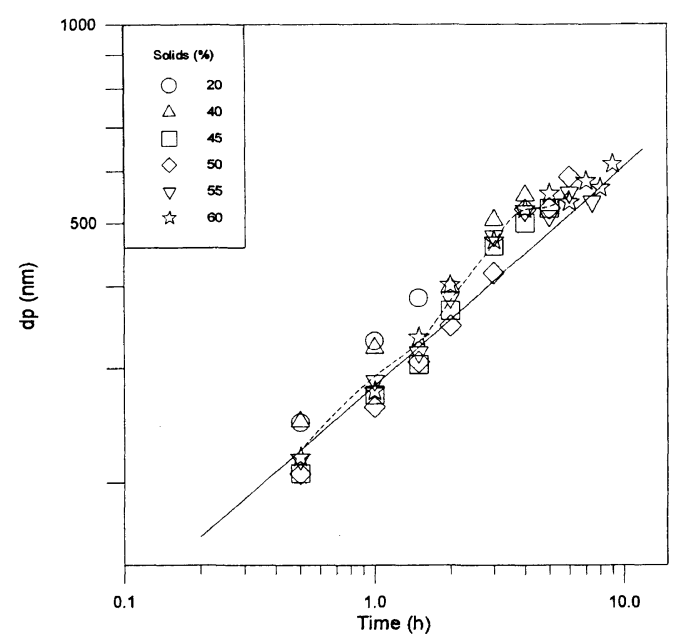

Figure 2. The latex particle size as a function of reaction time for experiments with various target total solids contents: $\bigcirc, 20 \% ; \triangle, 40 \% ; \square, 45 \% ; \diamond, 50 \% ; \nabla, 55 \%$; is, $60 \%$. 
of scrap collected at the end of the reaction was only $0.55 \%$ (based on total solids content) for the run with a total solids content of $20 \%$, the latex sample taken at $t=0.5 \mathrm{~h}$ had a much lower total solids content $(8.7 \%)$ and it should be much more stable. Thus, for comparison, a straight line with a slope of $1 / 3$ can be drawn through the average particle diameter data (an average of 6 data points) for the sample taken at $t=0.5 \mathrm{~h}$. The dashed line represents the curve that passes through the average particle diameter data of the latexes sampled at various reaction times.

The $d_{\mathrm{p}}$ data shown in Figure 2 deviate upward from the straight line with a slope of $1 / 3$, especially when the reaction time is greater than $2 \mathrm{~h}$. This observation implies that, in addition to conversion of the imbibed monomer to polymer in the particles, the latex particles also can grow through a limited flocculation process. The limited flocculation process causes the relatively unstable particles to aggregate together to reduce the particle surface area and, consequently, increase the particle surface charge density. The aggregated particles thus obtained can maintain an appreciable stability.

Another interesting feature of this series of experiments is that the shorter the reaction time (i.e., the lower the total solids content) is, the greater the scattering of the $d_{\mathrm{p}}$ data is (see Figure 2). At a lower total solids content (e.g., $8.7 \%$ at $t=0.5 \mathrm{~h}$ ), the colloidal system is less crowded and, therefore, the latex should be more stable. As a result, the reproducibility of the $d_{\mathrm{p}}$ data is quite poor because it is extremely difficult to control the particle size without using surfactants. As total solids content increases to a higher level (e.g., $40 \%$ at $t=4 \mathrm{~h}$ ), the reaction system becomes more crowded and the dispersed particles become less stable. As mentioned above, the limited flocculation process will come into play and provide the reaction system with some kind of particle size regulation mechanism. Hence, the reproducibility of the $d_{\mathrm{p}}$ data is greatly improved. In addition, the polydispersity index data of the particle size distribution $\left(d_{\mathrm{w}} / d_{\mathrm{n}}\right)$ listed in Table II show that most of the finished latex products have a relatively narrow particle size distribution.

Table II shows that the $\zeta$ of the finished products are within the range of $-90 \pm 10 \mathrm{mV}$. The relatively constant $\zeta$, along with the total amount of scrap and 200-mesh filterable solids data shown in Table II and the $d_{\mathrm{p}}$ data shown in Figure 2, strongly suggest that the colloidal system can maintain an appreciable stability during the monomer addition period primarily by limited flocculation of the relatively unstable latex particles. As mentioned above, the limited flocculation process tends to reduce the surface area of the growing particles and increase the particle surface charge density (i.e., $\zeta)$. On the other hand, intensive coagulation among the particles can result in the formation of coagulum.

In this series of experiments, the yields of the latex products are approximate $13 \%$ short of complete monomer conversion (see Table II). This deficiency is due to the slower polymerization rate for larger latex particles (i.e., smaller number of reaction loci) and formation of coagulum. A chaser (e.g., a thermal initiator or a redox system) can be added to the reaction medium to reduce the level of unreacted monomer immediately after the end of the monomer feed in the plant production.

\section{Effect of Agitation Speed}

Because the reaction system is under the influence of mechanical agitation, a velocity gradient will develop and this velocity gradient will increase both force and frequency of collision among the latex particles. As a consequence, the tendency of coagulation of the particles will increase with an increase in the agitation speed. On the other hand, an adequate mixing is required to disperse the monomer droplets well and improve the mass transfer of monomer and oligomeric radicals into the reaction loci under the emulsifier-free condition. Thus, the quality of the latex prod- 
Table II. Experimental data of the reaction time, total amount of scrap, 200-mesh filterable solids, particle size, particle size distribution $\left(d_{\mathrm{w}} / d_{\mathrm{n}}\right)$, and zeta potential $(\zeta)$ of the finished products

\begin{tabular}{|c|c|c|c|c|c|c|c|}
\hline & $\begin{array}{c}\text { Reaction } \\
\text { time }^{\mathbf{a}}\end{array}$ & Total scrap & $\begin{array}{l}\text { 200-mesh } \\
\text { flocs }\end{array}$ & $\begin{array}{l}\text { Particle } \\
\text { size }\end{array}$ & & $\zeta$ & Yield \\
\hline & $\mathrm{h}$ & $\%$ & ppm & $\mathrm{nm}$ & & $\mathrm{mV}$ & $\%$ \\
\hline \multicolumn{8}{|c|}{ Total solids content $/ \%$} \\
\hline 20 & 2.5 & 0.55 & 600 & 408 & 1.13 & -79 & 85 \\
\hline 40 & 5.0 & 0.14 & 39 & 561 & 1.10 & -100 & 94 \\
\hline 45 & 5.9 & 2.39 & 328 & 569 & 1.27 & -84 & 87 \\
\hline 50 & 7.0 & 1.67 & 196 & 583 & 1.13 & -82 & 85 \\
\hline 50 & 7.0 & 1.25 & 447 & 578 & 1.12 & -100 & 90 \\
\hline 55 & 8.4 & 1.55 & 50 & 585 & 1.17 & -84 & 83 \\
\hline 60 & 10.0 & 1.22 & 426 & 614 & 1.11 & -82 & 88 \\
\hline \multicolumn{8}{|c|}{ Agitation speed/rpm } \\
\hline 400 & 5.0 & 0.85 & 22 & 458 & 1.12 & -96 & 87 \\
\hline 600 & 5.0 & 0.14 & 39 & 561 & 1.10 & -100 & 94 \\
\hline 800 & 5.0 & 2.93 & 101 & 487 & 1.12 & -72 & 62 \\
\hline 800 & 5.0 & 21.74 & 75 & 492 & 1.09 & -67 & 60 \\
\hline 800 & 5.0 & 5.88 & 116 & 566 & 1.13 & -93 & 86 \\
\hline \multicolumn{8}{|c|}{ Monomer feed rate $/ \mathrm{g} \mathrm{min}^{-1}$} \\
\hline 0.74 & 5.0 & 0.45 & 84 & 451 & 1.08 & -88 & 81 \\
\hline 0.93 & 5.0 & 0.14 & 39 & 561 & 1.10 & -100 & 94 \\
\hline 1.49 & 5.0 & 4.56 & 35 & 490 & 1.18 & -80 & 88 \\
\hline \multicolumn{8}{|l|}{$[\mathrm{I}] / \%$} \\
\hline 0.13 & 5.0 & 9.25 & 286 & 490 & 1.15 & -67 & 61 \\
\hline 0.16 & 5.0 & 1.32 & 28 & 479 & 1.11 & -94 & 83 \\
\hline 0.19 & 5.0 & 0.14 & 39 & 561 & 1.10 & -100 & 94 \\
\hline 0.25 & 5.0 & 0.73 & 162 & 547 & 1.23 & -97 & 89 \\
\hline 0.31 & 5.0 & 0.72 & 296 & 359 & 1.13 & -99 & 87 \\
\hline \multicolumn{8}{|c|}{$\left[\mathrm{NaHCO}_{3}\right] / \%$} \\
\hline 0.065 & 5.0 & 1.10 & 23 & 388 & 1.09 & -84 & 85 \\
\hline 0.20 & 5.0 & 0.14 & 39 & 561 & 1.10 & -100 & 94 \\
\hline 0.33 & 5.0 & 2.49 & 22 & 491 & 1.05 & -93 & 88 \\
\hline
\end{tabular}

${ }^{\mathrm{a}}$ Including $1 \mathrm{~h}$ for consuming the residual monomer after the end of the monomer feed. ${ }^{\mathrm{b}} d_{\mathrm{w}} / d_{\mathrm{n}}$ is the polydispersity of the particle size distribution.

uct should be determined by the above two counteracting effects.

In this series of experiments, the agitation speed was varied from 400 to $800 \mathrm{rpm}$. Other parameters were kept constant: the total solids content was $40 \%$ at the end of the reaction, the monomer feed rate was $0.93 \mathrm{~g} \mathrm{~min}^{-1}$, and the concentration of the initiator and buffer was $0.19 \%$ and $0.20 \%$, respectively.

Figure 3 shows the $\log \left(d_{\mathrm{p}}\right)-v s .-\log (t)$ data for the experiments operated at different agitation speeds. For clarity, the $d_{\mathrm{p}}$ data for the run with an agitation speed of $600 \mathrm{rpm}$ (see
Figure 2) were replaced by the average circular data points and vertical bars hereinafter (see Figures 3-5 and 9). The total amount of scrap, 200-mesh filterable solids, $\zeta$, and yield of the finished products are listed in Table II. There is no apparent correlations between the agitation speed and $d_{\mathrm{p}}$ (see Figure 3 ) and between the agitation speed and total amount of scrap (see Table II). These observations are in consistent with the work of Shouldice et al. ${ }^{23}$ in which they showed that it was very difficult to control the particle size simply by varing the agitation speed for batch surfactant-free 
emulsion polymerization of styrene.

It is shown in Figure 3 that the $d_{\mathrm{p}}$ data for the run with an agitation speed of $400 \mathrm{rpm}$ almost fall on the straight line with a slope of $1 / 3$. This result indicates that limited flocculation of the latex particles during the monomer addition period is insignificant for the run with the lowest agitation speed. On the other hand, the $d_{\mathrm{p}}$ data for the run with an agitation speed of $800 \mathrm{rpm}$, although rather scattered, display a slope that deviates the most from the theoretical value $1 / 3$. Please note that the experiment with an agitation speed of $800 \mathrm{rpm}$ was carried out three times in order to confirm such a large deviation and, indeed, that was the case as shown by the closed triangular data points in Figure 3. This is because the run with the highest agitation speed generates the smallest latex particles and, hence, the greatest particle surface area during the early stage of polymerization (see the triangular data points in Figure 3). Such a surfactant-free emulsion polymerization system is very unstable and, therefore, the limited flocculation process can cause a rapid increase in the particle size during the monomer addition period. Recently, Song and Poehlein ${ }^{19}$ also found that the particle size increased with increasing agitation speed in the

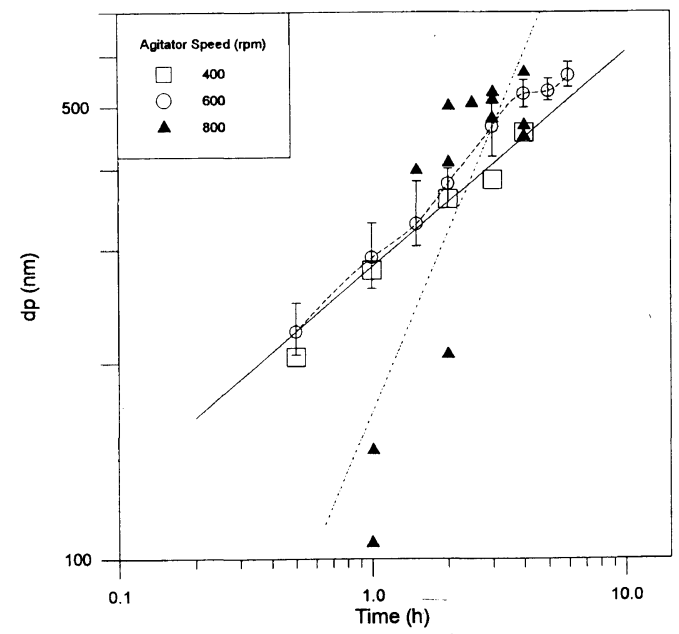

Figure 3. The latex particle size as a function of reaction time for experiments with various agitation speeds: $\square, 400$; 0,$600 ; \Delta, 800 \mathrm{rpm}$. batch surfactant-free emulsion polymerization of styrene. The total amount of scrap and 200mesh filterable solids of the finished product are the greatest for the run with the highest agitation speed. All the data suggest that the shear-induced coagulation process becomes important when the mechanical agitation is intensive.

\section{Effect of Monomer Feed Rate}

Three monomer feed rates were chosen for study in this series of experiments: $0.74,0.93$, and $1.49 \mathrm{~g} \mathrm{~min}^{-1}$. Other parameters were kept constant: the total solids content at the end of the monomer feed was $40 \%$, the agitation speed was $600 \mathrm{rpm}$, and the concentration of initiator and buffer was $0.19 \%$ and $0.20 \%$, respectively.

Figure 4 shows the $\log \left(d_{\mathrm{p}}\right)-v s .-\log (t)$ data for the runs with different monomer feed rates. As expected, at any time during the reaction the faster the monomer feed is, the larger the latex particle is. This can be explained by the fact that for the run with a faster monomer feed more monomer is available for polymerization inside the particles. Furthermore, intensive coagulation of the latex particles must have occurred during the monomer addition

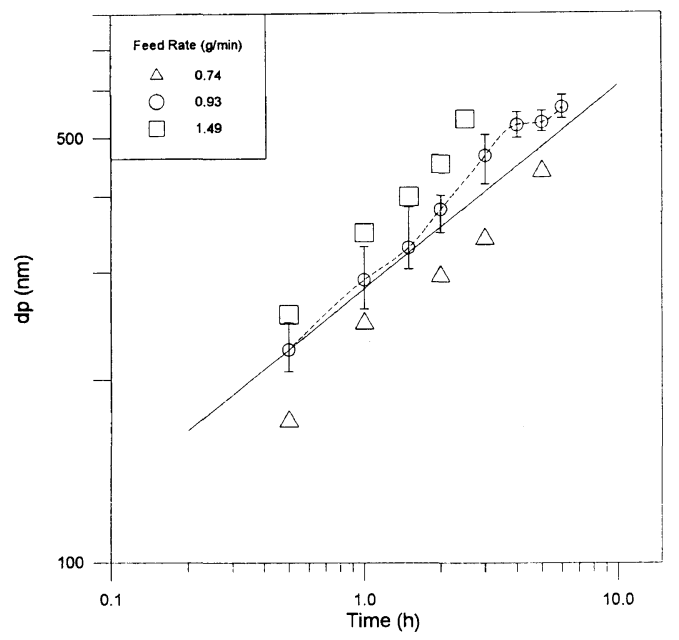

Figure 4. The latex particle size as a function of reaction time for experiments with different monomer feed rates: $\triangle, 0.74 ; \bigcirc, 0.93 ; \square, 1.49 \mathrm{~g} \mathrm{~min}^{-1}$. 
period for the run with the highest monomer feed rate (see the total amount of scrap data in Table II). The yields of the latex products are within $88 \pm 7 \%$ (see Table II). It is also interesting to note that the three sets of $d_{\mathrm{p}}$ data are almost in parallel with one another throughout the reaction. Thus, the extents of limited flocculation are about the same for this series of experiments. The experiments demonstrated here, again, show that the semibatch surfactant-free emulsion polymerization system is very sensitive to changes in the process variables such as the agitation speed, monomer feed rate, etc.

\section{Effect of Initiator Concentration}

In this series of experiments, the concentration of initiator was varied from $0.13 \%$ to $0.31 \%$. Other parameters were kept constant: the total solids content at the end of the reaction was $40 \%$, the agitation speed was $600 \mathrm{rpm}$, the monomer feed rate was $0.93 \mathrm{~g} \mathrm{~min}^{-1}$, and the concentration of buffer was $0.20 \%$. Figure 5 shows the $\log \left(d_{\mathrm{p}}\right)-v s .-\log (t)$ data for the experiments using various amounts of initiator. The total amount of scrap, 200-mesh filterable solids, $\zeta$, and yield of the finished products are

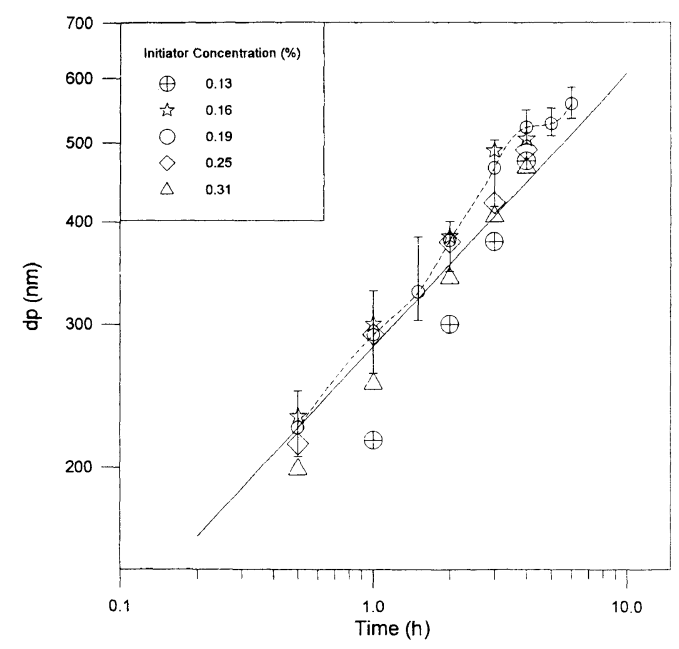

Figure 5. The latex particle size as a function of reaction time for experiments with various concentrations of initiator: $\oplus, 0.13 \%$;, $0.16 \% ; \bigcirc, 0.19 \% ; \diamond, 0.25 \% ; \triangle$, $0.31 \%$. compiled in Table II.

Goodwin et al., ${ }^{17}$ studied batch surfactantfree emulsion polymerization of styrene and they found that the particle size of the latex product was proportional to the initiator concentration to the 0.238 power. Figures 5 and 6 show that the initiator concentration has a significant effect on semibatch surfactant-free emulsion polymerization of BA. However, we do not observe a linear relationship between the data of $\log \left(d_{\mathrm{p}}\right)$ and $\log [\mathrm{I}]$ (see Figure 6), where [I] is the concentration of initiator in the initial reactor charge. As shown in Figure 6 , at any time during the monomer addition period, $d_{\mathrm{p}}$ first increases to a maximum and then decreases with increasing initiator concentration.

Table II indicates that the emulsion polymer containing the lowest [I] $(0.13 \%)$ is the least stable (total amount of scrap $=9.25 \%, 200$ mesh filterable solids $=286 \mathrm{ppm}, \zeta=-67 \mathrm{mV}$, yield $=61 \%$ ). This is simply because there is an insufficient supply of $\mathrm{SO}_{4}^{-}$end-groups to stabilize the growing particles and, as a result, intensive coagulation of the latex particles can take place during polymerization. The $\zeta$ of the latex product first increases rapidly and then levels off as [I] increases from $0.13 \%$ to $0.31 \%$.

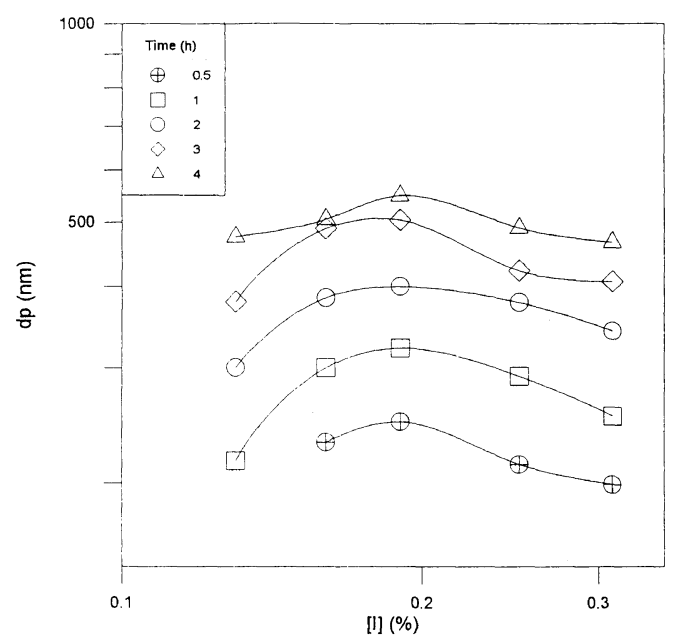

Figure 6. The latex particle size as a function of initiator concentration at different reaction times: $\oplus, 0.5 ; \square, 1 ; O$, $2 ; \diamond, 3 ; \triangle, 4 \mathrm{~h}$. 
However, the optimum colloidal stability cannot be achieved by adding as much initiator as possible to the reaction system because the concentration of electrolyte also increases with an increase in the initiator usage. The increased ionic strength will compress the electric double layer around the latex particles and reduce the potential energy barrier against coagulation. As a result, more coagulum will form during polymerization. The total amount of scrap, 200 -mesh filterable solids, $\zeta$, and yield of the finished products listed in Table II support this postulation. The optimum colloidal stability occurs at a point close to $[\mathrm{I}]=0.19 \%$.

Figure 7 shows the transmittance-vs.-log$[\mathrm{NaCl}]$ data with $\mathrm{pH}$ ranging from 3.7 to 11.0 , where $[\mathrm{NaCl}]$ is the concentration of sodium chloride. As expected, the transmittance of the latex sample is independent of $\mathrm{pH}$. It is shown that the transmittance remains relatively constant when $[\mathrm{NaCl}]$ is less than $c a .0 .4 \mathrm{~N}$, whereas it starts to increase rapidly after this salt concentration has been reached. The intersection $([\mathrm{NaCl}]=0.45 \mathrm{~N})$ between the two dashed lines shown in Figure 7 is thus identified as the CFC for the latex sample with a total solids content of $0.012 \%$. Figure 8 shows the $\zeta-v s$.$[\mathrm{NaCl}]$ data with various values of $\mathrm{pH}$ and,

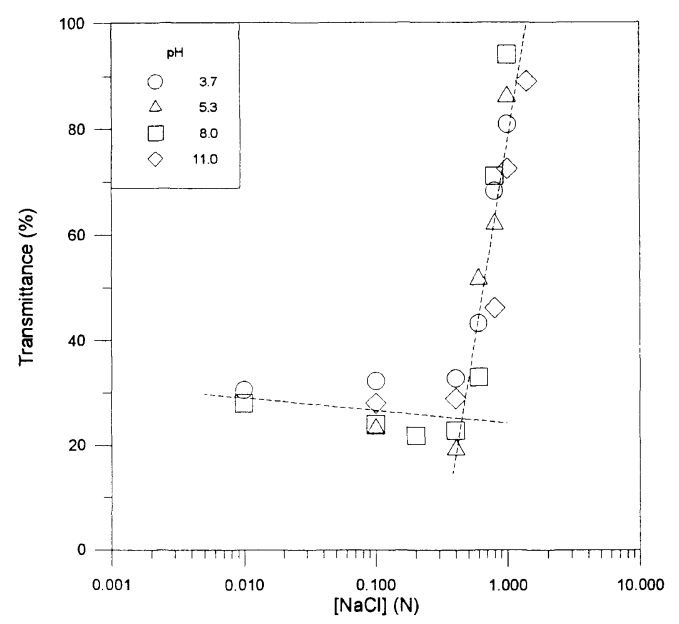

Figure 7. The transmittance of the latex sample as a function of $\mathrm{NaCl}$ concentration at various values of $\mathrm{pH}$ : ○, 3.7; $\triangle, 5.3 ; \square, 8.0 ; \diamond, 11.0$. again, the $\zeta$ of the latex particles is not affected by changing $\mathrm{pH}$. More importantly, it is shown that the $\zeta$ of the particles decreases significantly with increasing $[\mathrm{NaCl}]$. The colloidal system starts to lose its stability above CFC because the magnitude of $\zeta(c a .-20 \sim-30 \mathrm{mV})$ is no longer high enough to prevent the latex particles from coagulating with one another.

\section{Effect of Buffer Concentration}

In this series of experiments, the concentration of $\mathrm{NaHCO}_{3}$ was varied from $0.065 \%$ to $0.33 \%$. Other parameters were kept constant: the total solids content at the end of the reaction was $40 \%$, the agitation speed was $600 \mathrm{rpm}$, the monomer feed rate was $0.93 \mathrm{~g} \mathrm{~min}^{-1}$, and the concentration of initiator was $0.19 \%$.

Figure 9 shows the $\log \left(d_{\mathbf{p}}\right)-v s .-\log (t)$ data for the experiments using various amounts of $\mathrm{NaHCO}_{3}$ in the initial reactor charge. The total amount of scrap, 200-mesh filterable solids, $\zeta$, and yield of the finished products are listed in Table II. Figure 9 shows that at a common reaction time $d_{\mathrm{p}}$ increases significantly when the concentration of $\mathrm{NaHCO}_{3}\left(\left[\mathrm{NaHCO}_{3}\right]\right)$ increases from $0.065 \%$ to $0.20 \%$. The increased $d_{\mathrm{p}}$ can be attributed to the ionic strength effect as discussed below. The run with $\left[\mathrm{NaHCO}_{3}\right]$

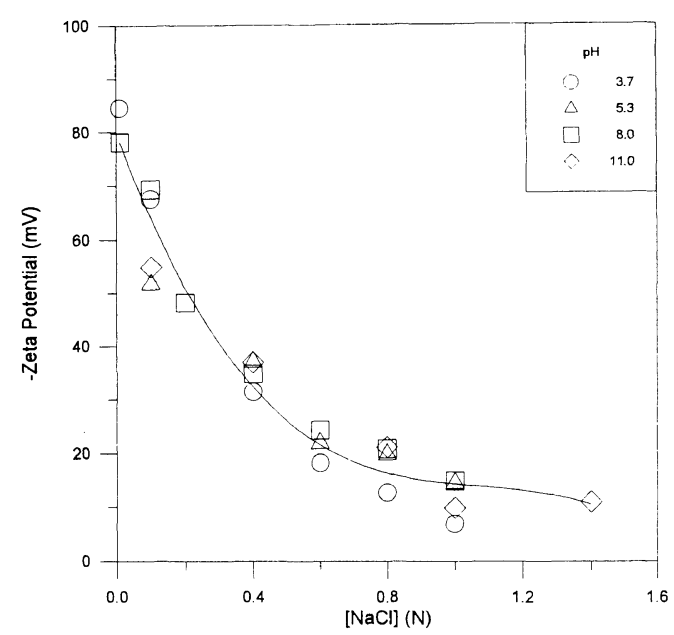

Figure 8. The zeta potential of the latex particles as a function of $\mathrm{NaCl}$ concentration at various values of $\mathrm{pH}$ : O, 3.7; $\triangle$, 5.3; $\square, 8.0 ; \diamond, 11.0$. 


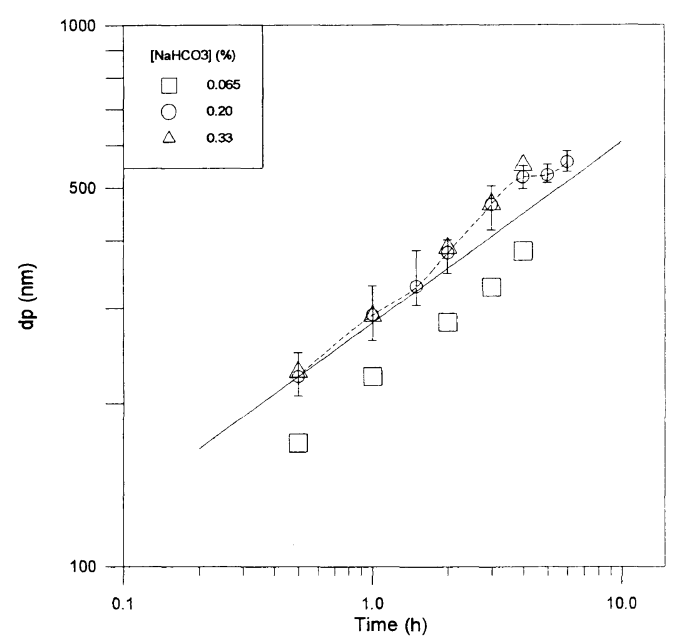

Figure 9. The latex particle size as a function of reaction time for experiments with various concentrations of sodium bicarbonate: $\square, 0.065 \% ; \bigcirc, 0.20 \% ; \triangle, 0.33 \%$.

equal to $0.065 \%$ has a lower electrolyte concentration and, thus, it can generate more latex particles during the early stage of polymerization (see the square data point at $t=0.5 \mathrm{~h}$ in Figure 9). However, the huge interfacial area renders the colloidal system relatively unstable and leads to significant coagulum formation (see the total amount of scrap and $\zeta$ data in Table II). On the other hand, the run with $\left[\mathrm{NaHCO}_{3}\right]$ equal to $0.20 \%$ has a higher electrolyte concentration and it should produce less latex particles during the early stage of polymerization (see the circular data point and vertical bar at $t=0.5 \mathrm{~h}$ in Figure 9). In this case, the moderate particle surface area results in a higher particle surface charge density (or $\zeta$ ) and a lower level of coagulum (see the total amount of scrap and $\zeta$ data in Table II).

Upon further increasing $\left[\mathrm{NaHCO}_{3}\right]$ from $0.20 \%$ to $0.33 \%$, the effect of buffer on the $\log \left(d_{\mathbf{p}}\right)-v s .-\log (t)$ profiles has vanished, as shown by the circular and triangular data points in Figure 9. Nevertheless, intensive coagulation of the latex particles still can happen during the reaction for the run with $\left[\mathrm{NaHCO}_{3}\right]$ equal to $0.33 \%$, again, due to the increasing ionic strength (see the total amount of scrap and $\zeta$ data in Table II). As mentioned above, the increased ionic strength will compress the electric double layer around the latex particles and reduce the potential energy barrier against coagulation. As a result, more coagulum will form during the monomer addition period.

\section{REFERENCES}

1. P. Fram, G. T. Stewart, and A. J. Szlochtum, Ind. Eng. Chem., 47, 1000 (1955).

2. B. G. Elgood, E. V. Gulbekian, and D. Kinsler, $J$. Polym. Sci., Part B, 2, 257 (1964).

3. R. A. Wessling, J. Appl. Polym. Sci., 12, 309 (1968).

4. H. Gerrens, J. Polym. Sci., Part C, 27, 77 (1969).

5. J. J. Krackeler and H. Naidus, J. Polym. Sci., Part C, 27, 207 (1969).

6. B. W. Greene, J. Colloid Interf. Sci., 43, 449 (1973).

7. B. W. Greene, J. Colloid Insterf. Sci., 43, 462 (1973).

8. P. Bataille, B. T. Van, and Q. B. Pham, J. Appl. Polym. Sci., 22, 3145 (1978).

9. J. Snuparek, Jr., J. Appl. Polym. Sci., 24, 909 (1979).

10. J. Snuparek, Jr. and A. Tutalkova, J. Appl. Polym. Sci., 24, 915 (1979).

11. R. W. Novak, Adv. Org. Coat. Sci. Technol. Ser., 10, 54 (1988).

12. B. Li and B. W. Brooks, Polym. Int., 29, 41 (1992).

13. C. S. Chern and H. Hsu, J. Appl. Polym. Sci., 55, 571 (1995).

14. T. Matsumoto and A. Ochi, Kobunshi Kagaku, 22, 48 (1965).

15. A. R. Goodall, M. C. Wilkinson, and J. Hearn, J. Polym. Sci., Polym. Chem. Ed., 15, 2193 (1977).

16. A. R. Goodall, J. Hearn, and M. C. Wilkinson, $B r$. Polym. J., 10, 141 (1978).

17. J. W. Goodwin, R. H. Ottewill, and R. Pelton, Colloid Polym. Sci., 257, 61 (1979).

18. D. Munro, A. R. Goodall, M. C. Wilkinson, K. Randle, and J. Hearn, J. Colloid Interface Sci., 68, I (1979).

19. Z. Song and G. W. Poehlein, J. Polym. Sci., Polym. Chem. Ed., 28, 2359 (1990).

20. R. M. Fitch, Br. Polym. J., 5, 467 (1973).

21. R. M. Fitch and C. H. Tsai, in "Polymer Colloids", R. M. Fitch, Ed., Plenum Press, New York, N.Y., 1971, pp 73-102.

22. F. L. Saunders, in "Advances in Emulsion Polymerization and Latex Technology," Vol. I, M. S. El-Aasser, Ed., 16th Annual Short Course, Lecture No. 10, Emulsion Polymers Institute, Lehigh University, Bethlehem, PA, 1985.

23. G. T. D. Shouldice, G. A. Vandezande, and A. Rudin, Eur. Polym. J., 30, 179 (1994). 